\title{
A Tradição na Produção de estatuetas Cicládicas (3.200-2.700 A.C.)
}

Francisco de Assis Sabadini ${ }^{1}$

RESUMO: As ilhas localizadas a sudeste do mar Egeu, denominadas Cíclades, foram palco para o florescimento de diferentes culturas durante o Período do Bronze Antigo (3.200 a 2.00o a.C.). Entre 2.700-2.300 a.C., uma cultura denominada Keros-Siros produziu inúmeros exemplares de estatuetas padronizadas estilisticamente, conhecidas como estatuetas do tipo canônico ou braços cruzados. A despeito da forte manutenção de elementos tradicionais na produção dessas peças, a existência de variações estilísticas não é incomum.O presente artigo busca identificar os principais traços estilísticos, bem como as variações existentes nas estatuetas produzidas pela cultura Keros-Siros.

PALAVRAS-Chave: Período do Bronze; Estatuetas; Cíclades; Arqueologia.

ABSTRACT: The islands located to the southeast of the Aegean, named Cyclades, were hosts to different cultures during the Early Bronze Age (3.200 BC to 2.000 BC). Between 2.700-2.300 BC, a culture called Keros-Siros produced innumerable specimens of figurines stylistically patterned, known as canonical type or folded arms. In spite of the strong maintenance of traditional elements in the production of these pieces, the existence of stylistic variations is not uncommon. This article seeks to identify the main stylistic features as well as the variations in the figurines produced by the Keros-Siros culture.

KEYWORDS: Bronze Age; Figurines; Cyclades; Archaeology.

Nossa intenção ao propor um estudo das estatuetas do Cicládico Antigo II (2.700-2.300 a.C.) não é desenvolver uma nova hipótese sobre a utilização destas pelos antigos habitantes das Cíclades, tampouco é oferecer subsídios para tal finalidade. ${ }^{2}$ Nossa proposta é um tanto mais modesta. Ela se concentra no estudo dos padrões estilísticos pelos quais a produção das estatuetas se pautou, bem como nas modificações que sofreram. Alguns detalhes que caracterizam as estatuetas foram conservados ao passo que outros foram paulatinamente modificados ao longo do tempo, sendo evidente a transformação gradual que resultou em variações na forma das estatuetas. São mudanças tênues que, quando analisadas na seriação cronológica, evidenciam um processo de mudança. Nesse

\footnotetext{
${ }^{1}$ Doutorando em Arqueologia no Museu de Arqueologia e Etnologia da Universidade de São Paulo. Bolsista CAPES. E-mail: franciscosabadini@gmail.com.

2 Para algumas hipóteses sobre as possíveis funções das estatuetas, como representação de deidades, objetos ritualísticos e brinquedos, ver Barber (1984, p. 10-14).
} 
sentido, este artigo visa contribuir para o estudo do padrão e variação estilística das estatuetas do tipo canônico ou braços cruzados do Cicládico Antigo II (2.7002.300 a.C.), apresentando de maneira mais detalhada as características que definem o tipo, ou seja, os elementos estilísticos essenciais. Em complemento, objetiva-se também identificar os elementos estilísticos subsidiários que não foram essenciais para a construção e manutenção do estilo, mas que acabaram por resultar em variações. Variações estas que podem ser organizadas cronologicamente. Embora a tipologia das estatuetas seja bastante conhecida, a bibliografia sobre o assunto a apresenta de maneira generalista, sem maiores detalhamentos e atenção as características que as definem.

\section{Estatuetas cicládicas}

As Cíclades posicionam-se entre a Europa e a Ásia, formando um arquipélago rico em recursos minerais. São verdadeiros pontos de parada e abastecimento no centro do Mar Egeu que fazem a ligação entre a Grécia e o Oriente Próximo para movimentações marítimas de diversas naturezas, favorecendo as trocas econômicas e culturais. Por outro lado, as condições internas e naturais das Cíclades - a maioria das ilhas possuem apenas pequenas parcelas de terras cultiváveis, escassas fontes de água potável e estão situadas em uma região de clima seco, pouco chuvoso e isoladas pelo mar - impulsionaram o espírito de seus habitantes na busca por desenvolvimento técnico e tecnológico (Doumas, 1979, p. 11). 


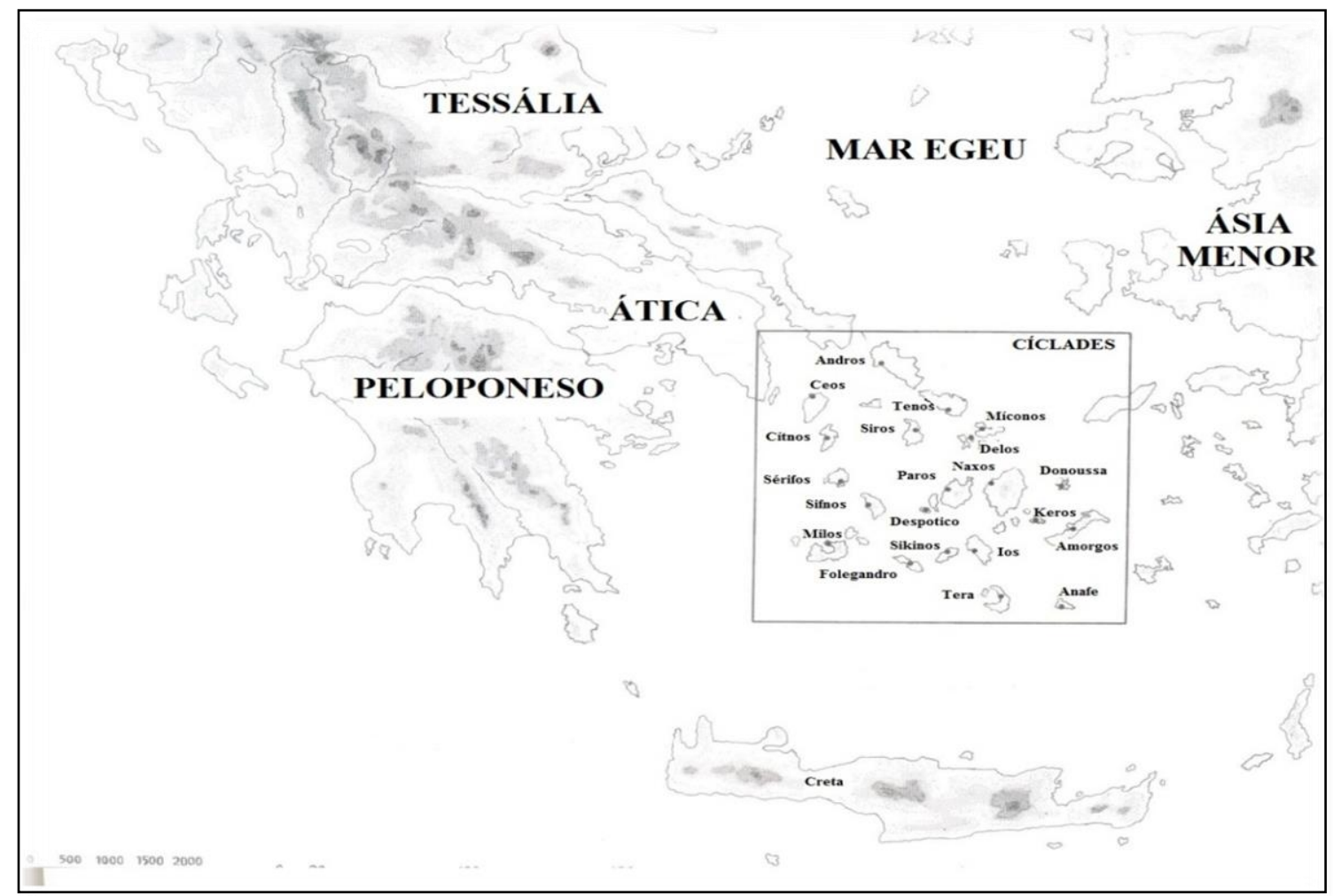

Fig. 1 -Mapa das regiões ao redor do mar Egeu, com destaque para a ilhas cicládicas. Fonte: adaptado de Doumas (2002, p. 20).

O interesse principal que temos na cultura material das Cíclades durante o terceiro milênio a.C. se deve a um motivo específico: sua tradição em produzir esculturas de mármore. Com tema naturalístico e antropomórfico, as esculturas foram talhadas em mármore e deixam entrever o nível técnico e o padrão estilístico da sociedade que as produziram. São artefatos como esses que, neste caso, conferem singularidade à cultura cicládica ao exibirem as peculiaridades da cultura material dessas ilhas. Essas peças são, portanto, vestígios atípicos dos padrões culturais contemporâneos a elas encontrados nas regiões no entorno do Egeu. Conforme apontam Preziosi e Hitchcock (1999, p. 54),

These finely made white marble idols have come to form a distinctive set of artefacts with very great appeal to modern collectors and fine art connoisseurs around the world, and they have come to be taken as uniquely distinctive of a Cycladic culture or cultures during the Early Bronze Age that still remains so poorly known in other ways, despite recent advances in archaeological knowledge. 3

\footnotetext{
3 Esses ídolos, graciosamente esculpidos em mármore, formam um conjunto de artefatos distintos que despertam interesse em colecionadores modernos e críticos de arte ao redor do mundo e são objetivos distintivos de uma cultura cicládica ou culturas do começo do Período do Bronze Antigo
} 
Por mais de mil anos o mármore foi usado pelos artesãos das Cíclades não apenas como suporte para trabalhos que dessem origem a vasos, mas também para esculpir figuras humanas (Doumas, 2002, p. 65). As características estilísticas das estatuetas indicam um longo período de mudança e transformação na imaginação e nas técnicas dos artesãos. Simples e abstratas no início, eram seixos em estado natural, algumas vezes com o mínimo de trabalho técnico para ganharem uma aparência que lembrasse a forma humana (ver fig. 2 imagens $1 \mathrm{e}$ 2). Com o tempo, elas se tornaram mais complexas e carregadas de grande disposição técnica. Essa tradição artística se manteve, com alguns intervalos, por milênios (Doumas, 2002, p. 64-68).

Nas camadas estratigráficas associadas ao terceiro milênio a.C., as representações humanas em mármore esculpido são encontradas em um leque de variações, do tipo esquemático no seixo até estátuas próximas do tamanho real humano. O mais notável é que durante o Cicládico Antigo I (3.200-2.800 a.C.) os modelos buscavam uma maior aproximação com a figura humana, resultando em muitas variações. Estatuetas desse período normalmente são achatadas e possuem alguns traços gravados para indicar certos detalhes anatômicos enquanto outros detalhes já são mostrados em relevo, o que lhes confere uma aparência tridimensional (figs. 2 imagens 8 e 9; 3 imagens 1 a 4).

Com a passagem para o Cicládico Antigo II (2.700-2.300 a.C.), as técnicas de manipulação da metalurgia se encontravam mais disseminadas, permitindo, assim, o aparecimento de ferramentas de bronze mais aprimoradas que as anteriores. 4 Essa inovação tecnológica capacitava o artesão a esculpir com maior precisão o mármore. As novas técnicas foram empregadas na produção de estatuetas talhadas em ambos os estilos: esquemático e representacional (figs. 2 e 3) achatadas em duas dimensões, embora uma tendência para modelos tridimensionais fosse bastante presente (Doumas, 2002, p. 66). Apesar das novas ferramentas de metais terem contribuído para a mudança estilística das estatuetas, elas não foram sozinhas o motivo dessa modificação tão grande em conceito e técnica. Assim como a metalurgia não é algo circunscrito ao conhecimento técnico de seu funcionamento - ela é fruto de uma circulação de

que ainda permanecem pouco conhecidos apesar do avanço do conhecimento arqueológico (Tradução livre).

4 As ferramentas de bronze não são uma inovação desse período. O que as camadas arqueológicas indicam é uma maior frequência do uso do metal durante o Cicládico Antigo II. 
ideias e conhecimentos -, as formas físicas das estatuetas também são, em parte, resultado de uma nova concepção "artística":

Durante todo el transcurso del tercer milenio antes de Jesucristo, la forma inicial de las estatuillas evoluciona y se transforma continuamente, aunque esta evolución no se debe exclusivamente al perfeccionamiento de las herramientas de bronce, sino también a las nuevas ideas que habían traído los marinos de las Ciclades de sus navegaciones (SapunaSakelaraki, 1978, p. 20).5

O formato típico das estatuetas do Cicládico Antigo II são as representações estilizadas com certas características que são encontradas somente associadas a esse período: são as chamadas estatuetas do tipo "canônico" ou "braços cruzados".

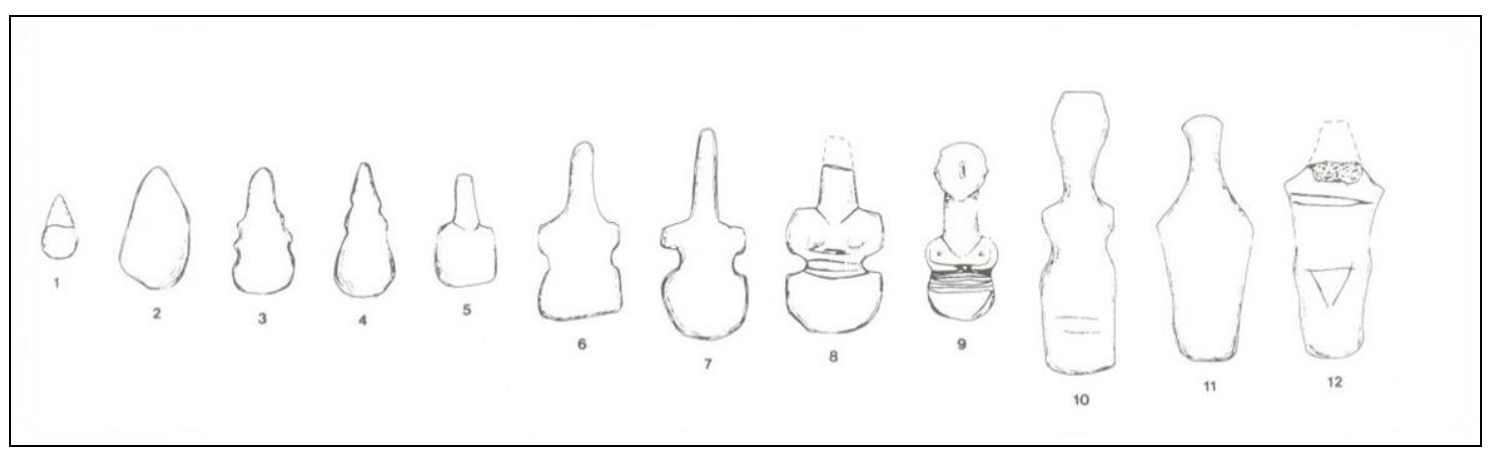

Fig. 2 -Estatuetas esquemáticas do Cicládico Antigo. Cicládico Antigo I: forma de seixo (1-2), quadripartite (3), tripartite (4), forma de pá (5), forma de violino (6-8), híbrida (9). Cicládico Antigo II (10-12). Fonte: Doumas (2002, p. 65)

5 Durante todo o curso do terceiro milênio a.C., a forma inicial das estatuetas se desenvolve e se transforma continuamente, apesar de que essa evolução não se deve exclusivamente ao aperfeiçoamento das ferramentas de bronze, mas também às novas ideias que haviam chegado com os marinheiros das Cíclades através de suas navegações (tradução livre). 


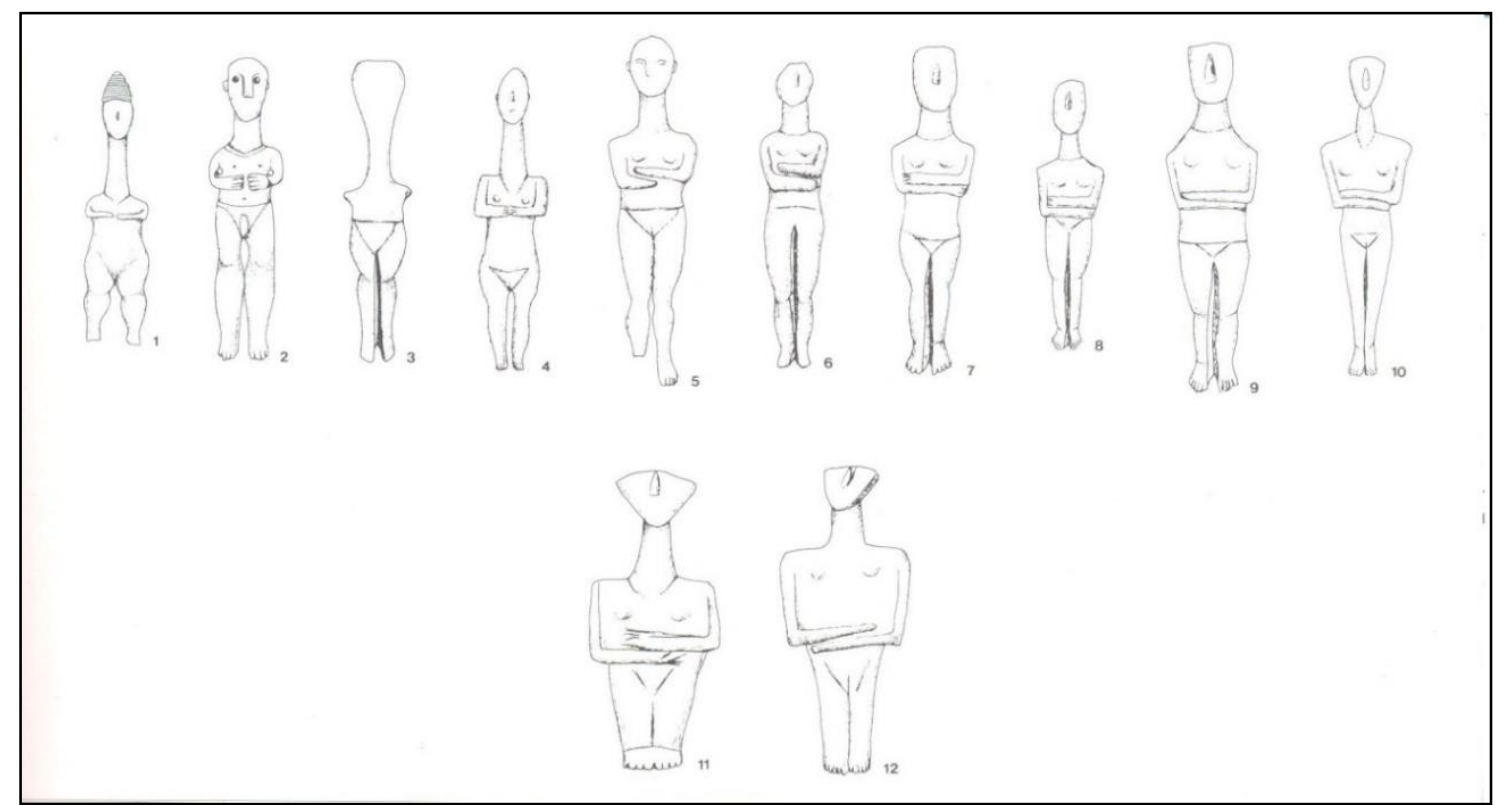

Fig. 3 - Estatuetas Representacionais. Cicládico Antigo I: tipo Plastiras (1,2,4), tipo Louros (3). Cicládico Antigo II: pré-canônica (5); canônica (6-11); pós-canônica (12).

Fonte: Doumas (2002, p. 65).

As origens desconhecidas e a perda dos contextos, em conjunto com a pequena quantidade de cemitérios e assentamentos escavados de forma apropriada para comparação, têm determinado os limites com que o estudioso trabalha em relação às estatuetas cicládicas. O que é possível é inferir que eram usadas como parte do aparelho funerário porque a maiorparte das peças encontradas em escavações sistemáticas são originárias de sepulturas (Doumas, 1979, p. 18).

Sequência cultural e as estatuetas canônicas

Como especificado anteriormente, a sequência cultural do Cicládico Antigo se apoia em dados estratigráficos e geográficos muitas vezes confusos devido a escavações antigas não muito documentadas, saques aos cemitérios e a própria disposição das camadas arqueológicas que não possuem uma sequência bem definida na maioria dos sítios, o que faz com que os arqueólogos completem informações por comparações de achados entre sítios nas Cíclades ou no Egeu (Renfrew, 1972, p. 135). Isso nos mostra um quadro cronológico pouco preciso, no qual as divisões de tempo são, na maioria das vezes, relativas. Não é objetivo deste artigo adentrar nos debates sobre os problemas da cronologia. ${ }^{6}$ Para o que

\footnotetext{
${ }^{6}$ Para mais informações, ver Renfrew (1972, p. 135-151).
} 
se propõe aqui - a variação na produção das estatuetas cícladicas - é suficiente estar ciente das divisões e distinções que até o momento a bibliografia sobre o Cicládico Antigo faz com base nos grupos de materiais.

A cultura mais antiga é denominada Grotta-Pelos (3.200-2.700 a.C.) e pode ser reconhecida pelos cemitérios com tumbas em forma de cista na parte central e sul das Cíclades. Os achados são provenientes de tumbas e assentamentos no sítio arqueológico Phylakopi, localizado na ilha de Milos, no sítio Grotta, na ilha de Naxos, e de outros sítios nas ilhas de Amorgos e Sifnos. Essa cultura é bem caracterizada, com distribuição coerente entre as ilhas mencionadas e materiais procedentes de sepulturas e assentamentos (Renfrew, 1972, p. 147).

Keros-Siros (2.700-2.300a.C.) é a segunda cultura na sequência cronológica do Cicládico Antigo.7 Foi primeiramente reconhecida e caracterizada nos objetos encontrados em cemitérios localizados nas ilhas do norte e centro do arquipélago cicládico e em achados periféricos, em sua maioria estatuetas do tipo "canônico/braços cruzados" nas ilhas do sul, como Ios e Tera. Vários cemitérios com material relacionado a essa cultura são conhecidos, como o sítio de Chalandriani em Siros, Dhaskalio em Keros, Monte Cinto em Delos e em Naxos. A cultura Keros-Siros, assim como a Grotta-Pelos, deve ser entendida como uma cultura bem definida das Cíclades durante o Período do Bronze Antigo (Renfrew, 1972, p. 147).

Dentre a coleção geral das estatuetas, selecionamos para este trabalho o tipo associado e característico da cultura material do grupo Keros-Siros (Renfrew, 1972, p. 175). Além dos braços cruzados, as estatuetas dessa cultura apresentam outras características, como cabeça modelada em formato de lira, inclinada para trás no topo; braços dobrados em $90^{\circ}$ no cotovelo, sendo que os antebraços apoiados no abdômen estão dispostos de maneira que o esquerdo fica sobre o direito; pernas levemente flexionadas nos joelhos sem serem modeladas separadas, mas divididas em direita e esquerda por uma incisão profunda, na frente e atrás, e com os pés estando sempre em uma posição na qual se apoiam nas pontas dos dedos. Estatuetas híbridas, combinando traços do tipo precedente, plastiras (fig. 3 imagens 1, 2 e 4), com os do tipo canônico são

${ }_{7}$ Segundo Colin Renfrew (1972, p. 149), a cultura Keros-Siros fica, em escala temporal, entre a cultura Grota-Pelos e Phylakopi I. 
caracterizadas como uma transição entre os dois modelos, portanto, são chamadas de tipo pré-canônico (fig. 3 imagem 5). Detalhes anatômicos e faciais não são comuns no tipo canônico, exceto o nariz que está sempre presente. Orelhas e olhos são raros e a boca, quando apresentada, discreta. Há, contudo, evidências de que estes detalhes faciais eram pintados em cores no mármore. Os prováveis pigmentos, feitos de minérios, usados nessas pinturas são encontrados em contextos cicládicos com frequência (Doumas, 2002, p. 66).

Estatuetas do Cicládico Antigo II do tipo canônico possuem entre 10 centímetros e 1.5 metros, padrão de dimensão maior que suas antecessoras do Cicládico Antigo I que possuíam cerca de 15 centímetros. A forte aderência aos traços estandardizados ao longo do Cicládico Antigo II não significa que não houvessem variações em função de diferentes oficinas ou artesãos operando em intervalos de tempo variados. Com base nos critérios mais gerais de proporção e forma encontrados nas estatuetas, esses desvios nos padrões exigiram uma subdivisão na classificação. Assim, o tipo canônico possui variações reconhecidas na sequência cronológica, sendo respectivamente: kapsala, spedos, dokathismata, koumasa e chalandriani (fig. 3 imagens 6 a 11). O que agrupa essas variações são traços gerais, sendo a própria denominação canônico ou braços cruzados indicativa das características encontradas em maior número nas peças, ou seja, aquilo que foge a essas normas são especificidades de cada variação. A sequência cronológica se baseia na seriação das estatuetas e sua maior ou menor afinidade estilística com o grupo anterior, o pré-canônico, ou com o grupo posterior, o pós-canônico. ${ }^{8}$ (Doumas, 2002, p. 66-68)

As variações são elementos bastante discretos que apontam pequenas mudanças ocorridas no tempo ou em função de oficinas e artesãos diferentes operando ao mesmo tempo, talvez com pequenas diferenças de anos entre um e outro. A produção das estatuetas, neste caso as do tipo canônico, estava submetida a dois fatores de maior importância. Em primeiro lugar, havia o controle externo imposto pelas normas culturais que ditavam como um tipo ou forma deveria ser executada. Por outro lado, havia o controle interno inconsciente exercido pelo estilo pessoal da oficina. Embora os artesãos do período trabalhassem sob o mesmo estilo conservador, cada indivíduo imprimia a sua

\footnotetext{
8 Para mais informações sobre a cronologia dos sítios e dos materiais associados à cultura KerosSiros, ver Renfrew (1972, p. 170-185).
} 
"assinatura" nas peças que produzia. Essa assinatura pode ser definida como um complexo de características que revelam os trabalhos como sendo mais próximos ou distantes uns dos outros. Certas formas, detalhes, aspectos, ângulos, adaptações particulares da forma canônica ou a combinação de alguns ou todos esses fatores se mantiveram imutáveis ou se modificaram seguindo certa lógica, permitindo, assim, que se identifique mudanças ao logo do tempo (Getz-Preziosi, 1984, p. 49). Essas mudanças podem ser agrupadas cronologicamente, embora não com muita precisão, nas cinco variações acima mencionadas (fig. 4).9

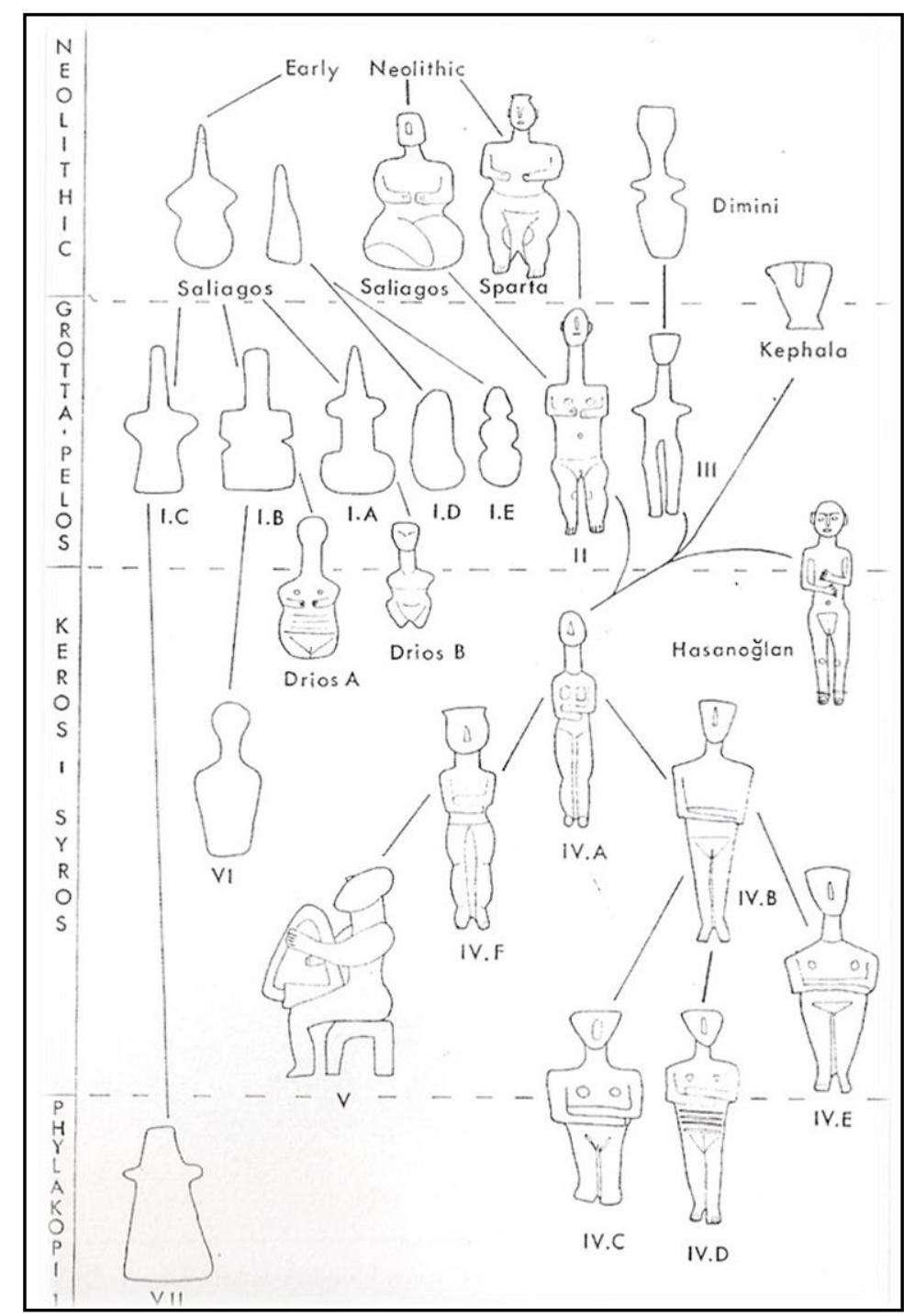

Fig. 4 - Desenvolvimento das estatuetas do Cicládico Antigo. Fonte: Renfrew (1972, p. 184).

\footnotetext{
9 As variações com as quais trabalhamos neste artigo estão relacionadas a cinco oficinas. Há, entretanto, também o estudo e atribuição a escultores específicos. Para mais informações, ver Doumas (1979, p. 21-27); Getz-Preziosi (1984, p. 48-74).
} 
A variedade kapsala (figs. 3 imagem 6; 4 imagem IV.A) possui linhas curvas, poucos detalhes em incisão e são muito parecidas com as estatuetas précanônicas (fig. 3 imagem 5). Essa variação, por exibir afinidades tipológicas com as estatuetas do tipo pré-canônicas, está cronologicamente no início da longa sequência das estatuetas canônicas, aproximadamente 2.700-2.300 a.C. (Doumas, 2002, p. 66-67). Já as estatuetas da variedade spedos (figs. 3 imagens 7 a 9; 4 imagem IV.F), receberam esse nome após serem encontradas no sítio Spedos, localizado no sul de Naxos. São volumosas na aparência e arredondadas. A cabeça é espessa com testa larga e formato de lira. O corpo é estreito com considerável diversidade em modelagem e proporção. Há poucos detalhes em incisão e os braços e pernas são esculpidos, coxas e tíbias separadas e os joelhos com leve flexão. Essa variação parece ter sido muito popular, fato que pode ser percebido devido à grande área por onde essas estatuetas estão distribuídas, assim como por sua grande diversidade de detalhes e tamanho, que vão de pequenos a muito grandes. Foram produzidas entre 2.700-2.300 a.C. (Doumas, 2002, p. 67).

A dokathismata (figs. 3 imagem 10; 4 imagem IV.B), variedade de Amorgos, inclui as estatuetas mais finas e elegantes criadas nas Cíclades. Caracterizadas por um afunilamento que parte dos ombros e se dirige aos pés, as peças possuem amplos ombros angulares e pernas finas com um sulco raso entre elas. Uma cabeça triangular com face plana em formato de escudo, nariz longo e aquilino e queixo proeminente são também características dessa variedade. Incisões são usadas para detalhes e os bustos são indicados com leves protuberâncias no peito (Doumas, 2002, p. 66-68).

A variedade koumasa recebe o nome em função do sítio em Creta, chamado Koumasa, onde essa tipologia foi reconhecida e inclui as estatuetas produzidas nessa ilha. Pode ser interpretada como um esforço para satisfazer a demanda da sociedade minoica por estatuetas cicládicas, produzindo-as localmente com base nos cânones da tradição das Cíclades. No geral, essas estatuetas são pequenas com amplos ombros angulares e membros atrofiados. São muito finas e planas com inclinação para trás no corpo e na cabeça. Esta última é diferenciada do pescoço por uma incisão rudimentar (Doumas, 2002, p. $68)$. 
Fechando o curso do desenvolvimento do tipo canônico estão as estatuetas da variedade chalandriani (figs. 3 imagem 11; 4 imagem IV.E) que receberam o nome devido à sua associação a um extenso cemitério chamado Chalandriani, em Siros. São muito planas, cabeça triangular, pescoço longo, ombros angulares, peito plano e pernas pequenas, sem ênfase nos joelhos. A cintura é quase ausente e em seu lugar existe um longo triângulo púbico gravado. Incisões superficiais são usadas para marcar os dedos das mãos e dos pés. Está claro nos exemplares mais tardios dessa variedade que a forte aderência à proporção e aos cânones começou a ser abandonada (Doumas, 2002, p. 68).

Os desvios frequentes produzidos pela variedade chalandriani em relação aos padrões estilísticos do tipo canônico produziram um tipo de estatueta classificado como pós-canônico (figs. 3 imagem 12; 4 imagem IV.C-D). Estatuetas desse tipo são menos proporcionais em relação às formas do tipo canônico. Nas peças mais antigas, alguns resquícios do tipo anterior são mantidos de forma menos padronizada e misturados a traços de tipo mais novos Por exemplo, pescoço curto, face oval e detalhes faciais em relevo como olhos, orelhas, sobrancelhas, boca, assim como a posição arqueada dos pés, são traços de estatuetas do tipo plastiras (figs. 3 imagens 1 a 4; 4 imagem II) que reaparecem nas estatuetas pós-canônicas. Os braços agora seguem nova ordenação, direito sobre o esquerdo (Doumas, 2002, p. 68) As vari.ões apresentadas constituem indícios de modificadores da cultura, podendo ser a expressão de grupos locais ou personalidades individuais que contribuíram para uma mudança estilística. ${ }^{10}$

Um fator que deve ser compreendido para o estudo das variações culturais - entre elas a produção de estatuetas -são as redes de contato e trocas no Egeu. Segundo Finley (1990, p. 19), "o Egeu sempre constituiu um caminho para ideias, técnicas e instituições, tanto no início do segundo milênio como em outras épocas." Transformações ocorridas na cultura cicládica em função dessas trocas são percebidas em longos períodos através da mudança da cultura material da mesma. Assim, as estatuetas cicládicas do Bronze Antigo foram escolhidas para o presente artigo porque sua produção foi grande, cobrindo desde o final do

${ }^{10}$ Mudanças individuais ou de grupos pequenos nos padrões das estatuetas podem ser percebidas nas formas particulares atribuídas a artistas individuais ou grupos artísticos que os arqueólogos chamam de "escultores". Cf. Doumas (2002, p. 64-68). 
quarto até o segundo milênio a.C. (3.200-2.000 a.C.) (Doumas, 2002, p. 22), o que torna fácil perceber as variações ao longo do tempo.

A grande quantidade de detalhes presentes nas estatuetas é uma característica interessante, pois possuem certa padronização estilística conforme o período no qual foram produzidos. As variações nesses padrões ao longo do tempo indicam a adoção de diferentes técnicas ou a mudança dos valores estilísticos que orientavam a produção de estatuetas. As alterações sutis nos padrões estilísticos foram um processo contínuo que levou a diferenças mais significativas no final do período analisado (2.700-2.300 a.C.), que corresponde à produção das estatuetas do tipo canônico ou braços cruzados. Essas peças possuem uma grande quantidade de elementos padronizados o que tornou viável a análise das modificações.

A forte aderência a um conjunto essencial de características pressupõe a existência de uma preferência estilística comum ao arquipélago cicládico. Por outro lado, as variações, subentendidas como produções derivadas da essencialidade da forma, ou seja, do cânone, implica na existência de particularidades locais ou pessoais que, aplicadas ao longo do tempo, atuam na constituições de variantes produzidas a partir de um conceito comum que pode ser sumarizado por meio das características mais padronizadas encontradas nessa produção e que pouco variaram (fig. 6). Embora não conheçamos de maneira precisa as funções para a qual as estatuetas foram produzidas, elas parecem refletir alguma forma de crença, padrão, valores ou concepção sociocultural. De acordo com Finley (1990, p. 26), "Como destinavam-se basicamente a acompanhar os mortos nos túmulos, [as estatuetas] refletem uma certa tendência ou concepção religiosa, que foi partilhada além dos limites da Cíclades." No entanto, ao contrário de Finley, preferimos não interpretar as funções e apenas apontar que as Cíclades e as outras regiões em que as estatuetas foram encontradas partilhavam uma tradição estilística.

O alcance da cultura Keros-Siros e seus contatos no Egeu são amplamente atestados pela distribuição de sua cultura material em diferentes partes (fig. 5). 


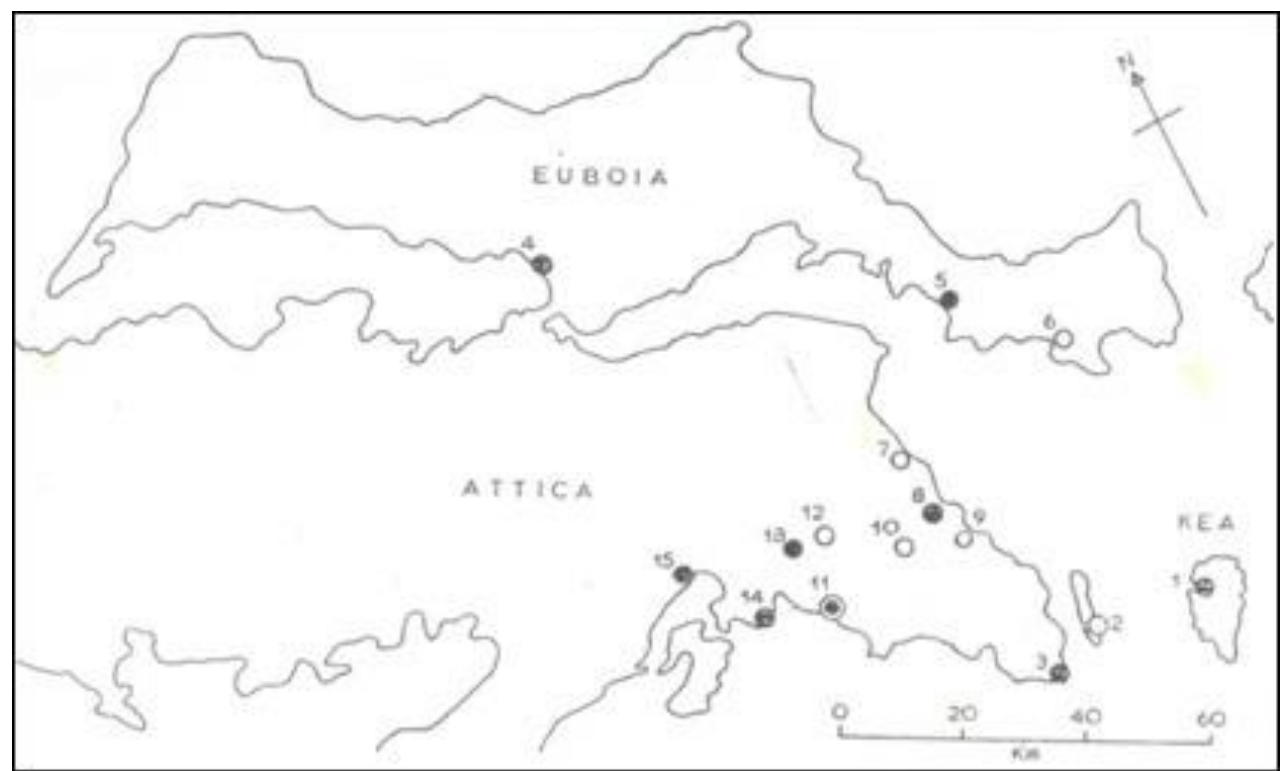

Fig. 5 - Distribuição de peças cicládicas em sítios na Ática e na Eubéia. Os pontos representam achados de estatuetas canônicas da cultura Keros-Siros e os círculos indicam túmulos contendo outras formas em mármore.1) Agia Irini, 2) Makrónisos, 3) Sounio, 4) Manika, 5) Styra, 6) Makrikapa, 7) Rafina, 8) Brauro, 9) Porto Rafti, 10) Markopoulo, 11) AghiosKosmas, 12) Chalandri, 13) Atenas, 14) Pireu, 15) Eleusis. Fonte: Renfrew (1972, p. 180)

As estatuetas circulavam em outras regiões por meio de comércio, negociação ou culto. Além disso, essas peças também eram frutos de normas e valores culturais, sejam eles estéticos, religiosos ou de outra natureza. Por último, é evidente que muitas das variações ocorreram por modificações estilísticas locais. Também é possível identificar estatuetas com traços próprios, talvez de um artista ou uma tradição local.

A seguir, apontaremos os traços diferentes entre as estatuetas, pois eles são representativos das variações.

Características tipológicas das estatuetas

Segue uma tabela que apresenta as características mais gerais das estatuetas analisadas. Privilegiou-se a escolha de peças já publicadas que são elucidativas das coleções do Museu de Arte Cicládica e do Museu Arqueológico Nacional de Atenas, ambos sediados na Grécia, e do Museu Paul Getty e do Museu de Belas Artes da Virgínia, sediados nos Estados Unidos. A preferência foi por estatuetas intactas ou que ainda estivessem com a maior parte dos detalhes íntegros, devido à necessidade de comparação e observação das características estilísticas em toda a superfície da peça. Dessa forma, 39 peças foram 
selecionadas, sobre as quais informações de registro e localização podem ser conferidas no anexo localizado no final do artigo.

\begin{tabular}{|c|c|c|c|c|c|c|c|c|c|c|c|c|c|c|c|c|c|}
\hline & $\mathbf{A}$ & B & $\mathbf{C}$ & D & $\mathbf{E}$ & $\mathbf{F}$ & $\mathbf{G}$ & $\mathbf{H}$ & $\mathbf{I}$ & $\mathbf{J}$ & $\mathbf{L}$ & $\mathbf{M}$ & $\mathbf{N}$ & $\mathbf{O}$ & $\mathbf{P}$ & $\mathbf{Q}$ & $\mathbf{R}$ \\
\hline 1 & $\mathrm{X}$ & & $\mathrm{X}$ & & & & $\mathrm{X}$ & & $\mathrm{X}$ & $\mathrm{X}$ & & $\mathrm{X}$ & & & $\mathrm{X}$ & $\mathrm{X}$ & \\
\hline 2 & $\mathrm{X}$ & & & $\mathrm{X}$ & & & $\mathrm{X}$ & & $\mathrm{X}$ & & $\mathrm{X}$ & $\mathrm{X}$ & & & $\mathrm{X}$ & $\mathrm{X}$ & \\
\hline 3 & $\mathrm{X}$ & & $X$ & & & & $\mathrm{X}$ & & $\mathrm{X}$ & & $\mathrm{X}$ & $\mathrm{X}$ & & & $\mathrm{X}$ & $\mathrm{X}$ & \\
\hline 4 & $\mathrm{X}$ & & & $X$ & & & $X$ & & $\mathrm{X}$ & & $\mathrm{X}$ & $\mathrm{X}$ & & & $\mathrm{X}$ & $\mathrm{X}$ & \\
\hline 5 & $\mathrm{X}$ & & & $\mathrm{X}$ & & & $\mathrm{X}$ & & $\mathrm{X}$ & & $\mathrm{X}$ & $\mathrm{X}$ & & & $\mathrm{X}$ & $\mathrm{X}$ & \\
\hline 6 & $\mathrm{X}$ & & & $\mathrm{X}$ & & $\mathrm{X}$ & & & $\mathrm{X}$ & $\mathrm{X}$ & & $\mathrm{X}$ & & & $\mathrm{X}$ & $\mathrm{X}$ & \\
\hline 7 & $\mathrm{X}$ & & & $\mathrm{X}$ & & & $\mathrm{X}$ & & $\mathrm{X}$ & & $\mathrm{X}$ & $\mathrm{X}$ & & & $\mathrm{X}$ & $\mathrm{X}$ & \\
\hline 8 & & $X$ & & $\mathrm{X}$ & & & $\mathrm{X}$ & & $\mathrm{X}$ & & $\mathrm{X}$ & $\mathrm{X}$ & & & $\mathrm{X}$ & $\mathrm{X}$ & \\
\hline 9 & $\mathrm{X}$ & & & $\mathrm{X}$ & & $\mathrm{X}$ & & $\mathrm{X}$ & & & $\mathrm{X}$ & $\mathrm{X}$ & & & $\mathrm{X}$ & $\mathrm{X}$ & \\
\hline 10 & $\mathrm{X}$ & & & $\mathrm{X}$ & & $\mathrm{X}$ & & & $\mathrm{X}$ & & $\mathrm{X}$ & $\mathrm{X}$ & & & $\mathrm{X}$ & $\mathrm{X}$ & \\
\hline 11 & $\mathrm{X}$ & & & $\mathrm{X}$ & & & $\mathrm{X}$ & & $\mathrm{X}$ & $\mathrm{X}$ & & $\mathrm{X}$ & & & $\mathrm{X}$ & $\mathrm{X}$ & \\
\hline 12 & $\mathrm{X}$ & & & $\mathrm{X}$ & & $\mathrm{X}$ & & $\mathrm{X}$ & & & $\mathrm{X}$ & $\mathrm{X}$ & & & $\mathrm{X}$ & $\mathrm{X}$ & \\
\hline 13 & $\mathrm{X}$ & & & $\mathrm{X}$ & & $\mathrm{X}$ & & & $\mathrm{X}$ & $\mathrm{X}$ & & $\mathrm{X}$ & & & $\mathrm{X}$ & $\mathrm{X}$ & \\
\hline 14 & $\mathrm{X}$ & & $X$ & & & & $\mathrm{X}$ & $\mathrm{X}$ & & & $\mathrm{X}$ & $\mathrm{X}$ & & & $\mathrm{X}$ & $\mathrm{X}$ & \\
\hline 15 & $\mathrm{X}$ & & & $\mathrm{X}$ & & $\mathrm{X}$ & & & $\mathrm{X}$ & $\mathrm{X}$ & & $\mathrm{X}$ & & & $\mathrm{X}$ & $\mathrm{X}$ & \\
\hline 16 & $\mathrm{X}$ & & & $\mathrm{X}$ & & $\mathrm{X}$ & & & $\mathrm{X}$ & $\mathrm{X}$ & & $\mathrm{X}$ & & & $\mathrm{X}$ & $\mathrm{X}$ & \\
\hline 17 & $\mathrm{X}$ & & & $\mathrm{X}$ & & & $\mathrm{X}$ & & $\mathrm{X}$ & & $\mathrm{X}$ & $\mathrm{X}$ & & & $\mathrm{X}$ & $\mathrm{X}$ & \\
\hline 18 & $\mathrm{X}$ & & & $\mathrm{X}$ & & $\mathrm{X}$ & & & $\mathrm{X}$ & & $\mathrm{X}$ & $\mathrm{X}$ & & & $\mathrm{X}$ & $\mathrm{X}$ & \\
\hline 19 & $\mathrm{X}$ & & $\mathrm{X}$ & & & & $\mathrm{X}$ & $\mathrm{X}$ & & $\mathrm{X}$ & & $\mathrm{X}$ & & & $\mathrm{X}$ & $\mathrm{X}$ & \\
\hline 20 & $\mathrm{X}$ & & & $\mathrm{X}$ & & $\mathrm{X}$ & & $\mathrm{X}$ & & & $\mathrm{X}$ & $\mathrm{X}$ & & & $\mathrm{X}$ & $\mathrm{X}$ & \\
\hline 21 & $\mathrm{X}$ & & & $\mathrm{X}$ & & $\mathrm{X}$ & & $\mathrm{X}$ & & & $\mathrm{X}$ & $\mathrm{X}$ & & & $\mathrm{X}$ & $\mathrm{X}$ & \\
\hline 22 & $\mathrm{X}$ & & & $\mathrm{X}$ & & & $\mathrm{X}$ & $\mathrm{X}$ & & $\mathrm{X}$ & & $\mathrm{X}$ & & $\mathrm{X}$ & & $\mathrm{X}$ & \\
\hline 23 & $\mathrm{X}$ & & & $\mathrm{X}$ & & & $\mathrm{X}$ & & $\mathrm{X}$ & & $\mathrm{X}$ & $\mathrm{X}$ & & & $\mathrm{X}$ & $\mathrm{X}$ & \\
\hline 24 & $\mathrm{X}$ & & & $\mathrm{X}$ & & $\mathrm{X}$ & & & $\mathrm{X}$ & $\mathrm{X}$ & & $\mathrm{X}$ & & & $\mathrm{X}$ & $\mathrm{X}$ & \\
\hline 25 & $\mathrm{X}$ & & & $\mathrm{X}$ & & $\mathrm{X}$ & & $\mathrm{X}$ & & $\mathrm{X}$ & & $\mathrm{X}$ & & $\mathrm{X}$ & & $\mathrm{X}$ & \\
\hline 26 & $\mathrm{X}$ & & & $\mathrm{X}$ & & $\mathrm{X}$ & $\mathrm{X}$ & $\mathrm{X}$ & . & & $\mathrm{X}$ & $\mathrm{X}$ & & & $\mathrm{X}$ & $\mathrm{X}$ & \\
\hline 27 & $\mathrm{X}$ & & & $\mathrm{X}$ & & & $\mathrm{X}$ & & $\mathrm{X}$ & & $\mathrm{X}$ & $\mathrm{X}$ & & $\mathrm{X}$ & & $\mathrm{X}$ & \\
\hline 28 & $\mathrm{X}$ & & & $\mathrm{X}$ & & $\mathrm{X}$ & & $\mathrm{X}$ & & $\mathrm{X}$ & & $\mathrm{X}$ & & & $\mathrm{X}$ & $\mathrm{X}$ & \\
\hline 29 & $\mathrm{X}$ & & & & $\mathrm{X}$ & & & & $\mathrm{X}$ & & $\mathrm{X}$ & & $\mathrm{X}$ & $\mathrm{X}$ & & & $\mathrm{X}$ \\
\hline 30 & $\mathrm{X}$ & & & & $\mathrm{X}$ & $\mathrm{X}$ & & $\mathrm{X}$ & & $\mathrm{X}$ & & & $\mathrm{X}$ & $\mathrm{X}$ & & $\mathrm{X}$ & \\
\hline 31 & $\mathrm{X}$ & & & $\mathrm{X}$ & & $\mathrm{X}$ & & $\mathrm{X}$ & & & $\mathrm{X}$ & & $\mathrm{X}$ & & $\mathrm{X}$ & $\mathrm{X}$ & \\
\hline 32 & $\mathrm{X}$ & & & $\mathrm{X}$ & & & $\mathrm{X}$ & & $\mathrm{X}$ & & $\mathrm{X}$ & & $\mathrm{X}$ & $\mathrm{X}$ & & $\mathrm{X}$ & \\
\hline 33 & $\mathrm{X}$ & & & & $\mathrm{X}$ & $\mathrm{X}$ & & & $\mathrm{X}$ & & $\mathrm{X}$ & & $\mathrm{X}$ & $\mathrm{X}$ & & $\mathrm{X}$ & \\
\hline 34 & $\mathrm{X}$ & & & & $\mathrm{X}$ & $\mathrm{X}$ & & & $\mathrm{X}$ & $\mathrm{X}$ & & & $\mathrm{X}$ & $\mathrm{X}$ & & $\mathrm{X}$ & \\
\hline 35 & $\mathrm{X}$ & & & & $\mathrm{X}$ & & $\mathrm{X}$ & & $\mathrm{X}$ & $\mathrm{X}$ & & & $\mathrm{X}$ & $\mathrm{X}$ & & $\mathrm{X}$ & \\
\hline 36 & & $X$ & & & $\mathrm{X}$ & & $\mathrm{X}$ & & $\mathrm{X}$ & $\mathrm{X}$ & & & $\mathrm{X}$ & $\mathrm{X}$ & & $\mathrm{X}$ & \\
\hline 37 & & $\mathrm{X}$ & $\mathrm{X}$ & & & & $\mathrm{X}$ & & $\mathrm{X}$ & & $\mathrm{X}$ & $\mathrm{X}$ & & $\mathrm{X}$ & & $\mathrm{X}$ & \\
\hline 38 & & $\mathrm{X}$ & $\mathrm{X}$ & & & $\mathrm{X}$ & & & $\mathrm{X}$ & & $\mathrm{X}$ & $\mathrm{X}$ & & $\mathrm{X}$ & & $\mathrm{X}$ & \\
\hline 39 & $\mathrm{X}$ & & & & & & & & & $\mathrm{X}$ & & $\mathrm{X}$ & & $\mathrm{X}$ & & $\mathrm{X}$ & \\
\hline
\end{tabular}

Fig. 6 - Disposição tipológica das estatuetas. Os números em coluna indicam as peças discriminadas na tabela do corpus e as letras indicam as características: A (braço esquerdo sobre o direito), $\mathrm{B}$ (braços direito sobre o esquerdo), $\mathrm{C}$ (cabeça ovalada), $\mathrm{D}$ (cabeça em formato de lira), E (cabeça triangular), F (nariz logo), G (nariz curto), $\mathrm{H}$ (nariz fino), I (nariz largo), $\mathrm{J}$ (pescoço longo), L (pescoço curto), $\mathrm{M}$ (ombros curvos), $\mathrm{N}$ (ombros geométricos), $\mathrm{O}$ (pernas retas), $\mathrm{P}$ (pernas curtas), Q (material mármore), R (material outros).

\section{Podemos perceber nessa tabela duas características comuns presentes} em todos exemplares do tipo canônico, que são os braços cruzados e o sexo feminino. Outras características que aparecem com frequência nas estatuetas selecionadas são: braço esquerdo sobre o direito, encontrado em 89,7\% dos casos, sendo que apenas quatro peças possuem o braço direito sobre o esquerdo, das quais três são pós-canônicas. Em $66,6 \%$ as estatuetas possuem a cabeça modelada no formato de lira, sendo que seis são ovais, seis triangulares e uma tem a cabeça como continuação do pescoço. Quanto ao nariz, o comum é a sua 
existência em relevo, pois nosso cálculo identificou 50\% longos e 50\% curtos; apenas a estatueta número 39 não possui indicativos de nariz. 66,6\% dos narizes são largos e 30,7\% finos, o que não torna o estilo do nariz tão significativo quanto sua presença. O pescoço também não possui uma diferença destacada entre os dois tipos, pois há uma frequência apenas ligeiramente maior do tipo curto. Os ombros curvilíneos são outra característica do tipo canônico (79,4\%). Apenas oito estatuetas possuem ombros angulares e essa característica é mais comum nos tipos pós-canônicos. Pernas flexionadas estão presentes em $66,6 \%$ das peças. Por último, o aspecto mais marcante é o material: 97,4\% das estatuetas são feitas de mármore; um único exemplar apenas é feito de pedra verde, provavelmente produzido fora das Cíclades.

A partir desses dados, concluímos que os aspectos mais destacados desse corpus documental, quais sejam, sexo feminino, braços cruzados com o esquerdo sobre o direito, ombros curvilíneos e o uso do mármore como suporte, são os elementos que mais caracterizam a produção de estatuetas da cultura Keros-Siros e a configuração tipológica mais resistente às mudanças ocorridas.

\section{Conclusão}

A partir da análise realizada, podemos afirmar que as estatuetas canônicas produzidas ao longo de quatro séculos (2.700-2.300 a.C.), apresentam indícios de mudança nos padrões com que foram feitas. Existia certa tradição na forma como deveriam ser produzidas, como demonstrado pela verificação tipológica das estatuetas, mas essa tradição sofreu alterações em função de intervenções dos artesãos locais que as produziram.

As características mais comuns na maioria das variações das estatuetas do tipo canônico são como a ideia central sobre a qual o conceito tipológico das estatuetas era concebido, algo essencial para essa forma artística que foi transmitido como valor cultural e padrão geral. A grande quantidade de elementos e detalhes anatômicos diferentes nelas presentes - sendo que alguns aparecem somente em um ou dois exemplares -, indicam a adaptação e interpretação desses valores e normas culturais. Em termos culturais, as variações nas estatuetas são uma espécie de apropriação e modificação dos valores presentes nas Cíclades, sejam esses valores religiosos, sociais, políticos ou 
estéticos. Tais adaptações ocorreram em âmbito externo e interno. Isso porque foram encontradas estatuetas fora das Cíclades feitas em outro suporte que não o mármore, ao passo que internamente, ou seja, no território cicládico, há variações na produção de estatuetas que podem indicar adaptações e ajustes locais.

As modificações são mais evidentes quando observadas na longa duração, pois mudanças causadas por intervenções de um grupo ou indivíduo demoram algumas gerações para que sejam perceptíveis na cultura material. Tomemos como exemplo um artesão hipotético do terceiro milênio a.C. que aprendeu com seu mestre os cânones e as formas com que as estatuetas eram demandadas pela sociedade cicládica. Em determinado momento, dando forma ao branco mármore, ele decide modificar o desenho do nariz e a forma como as pernas eram representadas, sendo que nos seus próximos trabalhos vai adotar tais inovações e transmiti-las a seus discípulos. Cinco ou dez anos depois, os então discípulos se tornam mestres que podem operar novas modificações ou manter a configuração que aprenderam. Fato é que as estatuetas que esses novos escultores produzirão já carregarão, em parte, diferenças em relação aos modelos vigentes na época que ainda aprendiam a arte. Caberia como efeito multiplicador desse processo a possibilidade de um dos novos artesãos se mudar ou ensinar a técnica para um suposto habitante de Creta. Este, por sua vez, produziria suas estatuetas em outro material, uma vez que o mármore não é abundante em Creta. No final, se comparássemos este último produto com as peças do primeiro artesão da cadeia hipotética de ensino e aprendizado, veríamos duas estatuetas com certos traços gerais em comum, o que denotaria certa proximidade tipológica, mas um olhar um pouco mais atento seria suficiente para identificar variações nos modelos.

A conclusão final é que as estatuetas são as evidências materiais de uma tradição não definida quanto à sua natureza, mas amplamente disseminada nas Cíclades. Tal tradição foi partilhada por outras regiões do Egeu. Aqueles que estavam em contato com ela a adaptaram, interpretaram e até a ressignificaram conforme as especificidades de grupos locais e culturais. Isso resultou em transformações tanto no campo material, isto é, as estatuetas e as variações nas suas características, quanto imaterial da cultura, ou seja, os significados e funções que essas estatuetas tinham dentro da sociedade. Devido ao não registro do contexto arqueológico de muitas estatuetas escavadas clandestinamente, há certa 
dificuldade em se compreender como elas eram utilizadas pela sociedade, sendo, portanto, mais numerosas as informações de mudanças estilísticas.

As estatuetas são, portanto, testemunhos de uma longa tradição de produção que, embora tenha mantido um padrão canônico, sofreu pequenas variações ao longo do tempo em sua forma e detalhes, resultando no abandono dos cânones no final do Cicádico Antigo II (2.700-2.300 a.C.). O motivo de tais variações é ainda bastante incerto, entretanto, há uma forte possibilidade de que esteja relacionado à existência ou surgimento de diferentes oficinas e escultores que acabaram por recriar os cânones da produção devido a preferências pessoais, técnicas particulares, preferências da demanda ou competição.

Artigo recebido em 03.09.2018, aprovado em 10.02.2019.

\section{REFERÊNCIAS BIBLIOGRÁFICAS}

Barber, Robin L.N. Early cycladic marble figurines: Some thoughts on function. In: Fitton, J.L. (ed.) Cycladica: Studies in Memory of N.P. Goulandris. Oxford: Oxford University Press, 1984.

Doumas, Christos. Cycladic Art: Ancient Sculpture and Ceramics of the Aegean From the N.P. Goulandris Collection. Baltimore: Schneidereith \& Sons, 1979.

. Silent Witnesses: Early Cycladic Art of the Third Millennium BC. New York: Alexander S. Onassis Public Benefit Foundation, 2002.

Finley, Moses. Grécia Primitiva: Idade do Bronze e Idade Arcaica. São Paulo: Martins Fontes, 1990.

Getz-Preziosi, Pat. Five sculptors in the Goulandris Collection. In: Fitton, Josephine L. (ed.) Cycladica: Studies in Memory of N.P. Goulandris. Oxford: Oxford University Press, 1984.

Museum of Cycladic Art, Atenas, Grécia. Disponível em: <https://cycladic.gr/en/page/kikladiki-techni>. Acesso em: 19 jan. 2019.

Nacional Archeological Museum of Athens, Atenas, Grécia. Disponível em: <https://www.namuseum.gr/en/collection/syllogi-kykladikon-archaiotiton/>. Acesso em: 19 jan. 2019.

Preziosi, Donald; Hitchcock, Louise A. Aegean Art and Architecture. Oxford: Oxford University Press, 1999.

Renfrew, Colin. The Emergence of Civilisation: The Cyclades and the Aegean in the Third Millennium BC. London: Methuen, 1972.

Sapuna-Sakelaraki, Efi. La Civilización Cicládica y la Colección Cicládica del Museo Nacional Arqueológico de Atenas.Vitoria: H. Fournier, 1978. 
The J. Paul Getty Museum, Los Angeles, Estados Unidos. Disponível em: <http://www.getty.edu/art/antiquities/>. Acesso em: 19 jan. 2019.

Virginia Museum of Fine Arts, Virginia, Estados Unidos. Disponível em: $<$ https://www.vmfa.museum/collections/ancient-art/>. Acesso em: 19 jan. 2019.

\section{ANEXO}

Tabela com informações resumidas sobre as estatuetas analisadas

\begin{tabular}{|c|c|c|c|c|}
\hline Peça & $\begin{array}{c}\text { Tamanho } \\
\mathbf{e} \\
\text { material }\end{array}$ & Contexto & $\begin{array}{c}\text { Classificação } \\
\text { e } \\
\text { coleção }\end{array}$ & Referência \\
\hline 1 & $\begin{array}{l}\text { Mármore } \\
28,5 \mathrm{~cm}\end{array}$ & ? & $\begin{array}{l}\text { - Cicládico Antigo I/II } \\
\text { Fase de transição pré-canônica } \\
\text { (2.80o-2.700 a.C.) } \\
\text { - Museu J. Paul Getty, Número } \\
\text { de inv. 72.AA.156 }\end{array}$ & $\begin{array}{l}\text { Doumas (2002, p. 74) } \\
\text { The J. Paul Getty Museum. Disponível em: } \\
\text { <http://www.getty.edu/art/gettyguide/art } \\
\text { ObjectDetails?artobj=8097>. Acesso em: } \\
\text { 19 jan. 2019. }\end{array}$ \\
\hline 2 & $\begin{array}{l}\text { Mármore } \\
49 \mathrm{~cm}\end{array}$ & $?$ & $\begin{array}{l}\text { - Cicládico Antigo II (2.700- } \\
\text { 2.300 a.C.), tipo } \\
\text { canônico/braços cruzados } \\
\text { (variedade kapsala) } \\
\text { - Museu J. Paul Getty, Número } \\
\text { de inv. 88.AA.78 }\end{array}$ & $\begin{array}{l}\text { Doumas (2002, p. } 75 \text { ) } \\
\text { The J. Paul Getty Museum. Disponível em: } \\
\text { <http://www.getty.edu/art/gettyguide/art } \\
\text { ObjectDetails?artobj=15052>. Acesso em: } \\
19 \text { jan. } 2019 \text {. }\end{array}$ \\
\hline 3 & $\begin{array}{c}\text { Mármore } \\
?\end{array}$ & $?$ & $\begin{array}{l}\text { - Cicládico Antigo II (.2700- } \\
2.300 \text { a.C.), tipo canônico/ } \\
\text { braços cruzados (variedade } \\
\text { kapsala) } \\
\text { - Museu Arqueológico } \\
\text { Nacional de Atenas, Número } \\
\text { de inv. } 4719\end{array}$ & Sapuna-Sakelaraki (19--?, p. 37) \\
\hline 4 & $\begin{array}{l}\text { Mármore } \\
16,5 \mathrm{~cm}\end{array}$ & ? & $\begin{array}{l}\text { - Cicládico Antigo II (2.700- } \\
\text { 2.300 a.C.), tipo } \\
\text { canônico/braços cruzados } \\
\text { (variedade kapsala) } \\
\text { - Museu de Arte Cicládica, } \\
\text { Número de inv. } 103\end{array}$ & Doumas (1979, p. 81) \\
\hline 5 & $\begin{array}{l}\text { Mármore } \\
25,3 \mathrm{~cm}\end{array}$ & $?$ & $\begin{array}{l}\text { - Cicládico Antigo II (2.700- } \\
\text { 2.300 a.C.), tipo } \\
\text { canônico/braços cruzados } \\
\text { (variedade kapsala, com } \\
\text { algumas características } \\
\text { spedos) } \\
\text { - Museu de Arte Cicládica, } \\
\text { Número de inv. } 595\end{array}$ & $\begin{array}{l}\text { Doumas (1979, p. 8o) } \\
\text { Museum of Cycladic Art. Disponível em: } \\
\text { <https://cycladic.gr/en/page/kikladiki- } \\
\text { techni>. Acesso em: } 19 \text { jan. 2019. }\end{array}$ \\
\hline 6 & $\begin{array}{l}\text { Mármore } \\
47,2 \mathrm{~cm}\end{array}$ & ? & $\begin{array}{l}\text { - Cicládico Antigo II (2.700- } \\
\text { 2.300 a.C.), tipo canônico/ } \\
\text { braços cruzados (variedade } \\
\text { kapsala, com algumas } \\
\text { características spedos) } \\
\text { - Museu de Arte Cicládica, } \\
\text { Número de inv. } 332\end{array}$ & Doumas (1979, p. 99) \\
\hline 7 & $\begin{array}{l}\text { Mármore } \\
49,5 \mathrm{~cm}\end{array}$ & ? & $\begin{array}{l}\text { - Cicládico Antigo II (2.700- } \\
\text { 2.300 a.C.), tipo canônico/ } \\
\text { braços cruzados (variedade } \\
\text { spedos antigo) } \\
\text { - Museu J. Paul Getty, Número } \\
\text { de inv. 88.AA.79 }\end{array}$ & $\begin{array}{l}\text { Doumas (2002, p. } 77 \text { ) } \\
\text { The J. Paul Getty Museum. Disponível em: } \\
\text { <http://www.getty.edu/art/gettyguide/art } \\
\text { ObjectDetails?artobj=15053>. Acesso em: } \\
19 \text { jan. 2019. }\end{array}$ \\
\hline 8 & $\begin{array}{c}\text { Mármore } \\
18,6 \mathrm{~cm}\end{array}$ & ? & $\begin{array}{l}\text { - Cicládico Antigo II (2.700- } \\
\text { 2.300 a.C.), tipo } \\
\text { canônico/braços cruzados } \\
\text { (variedade spedos antigo) } \\
\text { - Museu de Arte Cicládica, } \\
\text { Número de inv. 104a }\end{array}$ & Doumas (1979, p. 50) \\
\hline 9 & $\begin{array}{l}\text { Mármore } \\
25,4 \mathrm{~cm}\end{array}$ & ? & $\begin{array}{l}\text { - Cicládico Antigo II (2.700- } \\
2.300 \text { a.C.), tipo } \\
\text { canônico/braços cruzados } \\
\text { (variedade spedos antigo) }\end{array}$ & Doumas (1979, p. 51) \\
\hline
\end{tabular}




\begin{tabular}{|c|c|c|c|c|}
\hline & & & $\begin{array}{l}\text { - Museu de Arte Cicládica, } \\
\text { Número de inv. } 207\end{array}$ & \\
\hline 10 & $\begin{array}{l}\text { Mármore } \\
35,6 \mathrm{~cm}\end{array}$ & ? & $\begin{array}{l}\text { - Cicládico Antigo II (2.700- } \\
\text { 2.30o a.C.), tipo } \\
\text { canônico/braços cruzados } \\
\text { (variedade spedos antigo) } \\
\text { - Museu de Arte Cicládica, } \\
\text { Número de inv. } 52\end{array}$ & $\begin{array}{l}\text { Doumas (1979, p. 54) } \\
\text { Museum of Cycladic Art. Disponível em: } \\
\text { <https://cycladic.gr/en/page/kikladiki- } \\
\text { techni>. Acesso em: } 19 \text { jan. } 2019 .\end{array}$ \\
\hline 11 & $\begin{array}{l}\text { Mármore } \\
17,3 \mathrm{~cm}\end{array}$ & ? & $\begin{array}{l}\text { - Cicládico Antigo II (2.700- } \\
\text { 2.30o a.C.), tipo } \\
\text { canônico/braços cruzados } \\
\text { (variedade spedos antigo) } \\
\text { - Museu de Arte Cicládica, } \\
\text { Número de inv. } 104\end{array}$ & Doumas (1979, p. 62) \\
\hline 12 & $\begin{array}{l}\text { Mármore } \\
36,7 \mathrm{~cm}\end{array}$ & ? & $\begin{array}{l}\text { - Cicládico Antigo II (2.700- } \\
\text { 2.30o a.C.), tipo } \\
\text { canônico/braços cruzados } \\
\text { (variedade Spedos Antigo) } \\
\text { - Museu de Arte Cicládica, } \\
\text { Número de inv. } 253\end{array}$ & Doumas (1979, p. 65) \\
\hline 13 & $\begin{array}{l}\text { Mármore } \\
14,8 \mathrm{~cm}\end{array}$ & ? & $\begin{array}{l}\text { - Cicládico Antigo II (2.700- } \\
\text { 2.300 a.C.), tipo } \\
\text { canônico/braços cruzados } \\
\text { (variedade spedos antigo) } \\
\text { - Museu de Arte Cicládica, } \\
\text { Número de inv. } 462 \\
\end{array}$ & Doumas (1979, p. 87) \\
\hline 14 & $\begin{array}{l}\text { Mármore } \\
59,9 \mathrm{~cm}\end{array}$ & ? & $\begin{array}{l}\text { - Cicládico Antigo II (2.700- } \\
\text { 2.300 a.C.), tipo } \\
\text { canônico/braços cruzados } \\
\text { (variedade spedos tardio) } \\
\text { - Museu J. Paul Getty, Número } \\
\text { de inv. 88.AA.8o }\end{array}$ & $\begin{array}{l}\text { Doumas (2002, p. 79) } \\
\text { The J. Paul Getty Museum. Disponível em: } \\
\text { <http://www.getty.edu/art/gettyguide/art } \\
\text { ObjectDetails?artobj=15054>. Acesso em: } \\
\text { 19 jan. 2019. }\end{array}$ \\
\hline 15 & $\begin{array}{l}\text { Mármore } \\
33 \mathrm{~cm}\end{array}$ & ? & $\begin{array}{l}\text { - Cicládico Antigo II (2.700- } \\
\text { 2.300 a.C.), tipo } \\
\text { canônico/braços cruzados } \\
\text { (variedade spedos tardio) } \\
\text { - Museu de Arte Cicládica, } \\
\text { Número de inv. } 251\end{array}$ & Doumas (2002, p. 8o) \\
\hline 16 & $\begin{array}{l}\text { Mármore } \\
63,4 \mathrm{~cm}\end{array}$ & ? & $\begin{array}{l}\text { - Cicládico Antigo II(datas), } \\
\text { tipo canônico/braços cruzados } \\
\text { (variedade spedos tardio) } \\
\text { - Museu de Arte Cicládica, } \\
\text { Número de inv. } 281\end{array}$ & Doumas (1979, p. 56) \\
\hline 17 & $\begin{array}{l}\text { Mármore } \\
48 \mathrm{~cm}\end{array}$ & ? & $\begin{array}{l}\text { - Cicládico Antigo II (datas), } \\
\text { tipo canônico/braços cruzados } \\
\text { (variedade spedos tardio) } \\
\text { - Museu de Arte Cicládica, } \\
\text { Número de inv. } 654\end{array}$ & Doumas (1979, p. 58) \\
\hline 18 & $\begin{array}{l}\text { Mármore } \\
15,7 \mathrm{~cm}\end{array}$ & ? & $\begin{array}{l}\text { - Cicládico Antigo II (2.700- } \\
\text { 2.300 a.C.), tipo } \\
\text { canônico/braços cruzados } \\
\text { (variedade spedos tardio) } \\
\text { - Museu de Arte Cicládica, } \\
\text { Número de inv. } 309\end{array}$ & Doumas (1979, p. 66) \\
\hline 19 & $\begin{array}{l}\text { Mármore } \\
72 \mathrm{~cm}\end{array}$ & ? & $\begin{array}{l}\text { - Cicládico Antigo II (2.700- } \\
\text { 2.300 a.C.), tipo } \\
\text { canônico/braços cruzados } \\
\text { (variedade spedos tardio) } \\
\text { - Museu de Arte Cicládica, } \\
\text { Número de inv. } 598\end{array}$ & Doumas (1979, p. 107) \\
\hline 20 & $\begin{array}{l}\text { Mármore } \\
1,52 \mathrm{~cm}\end{array}$ & ? & $\begin{array}{l}\text { - Cicládico Antigo II (2.700- } \\
\text { 2.300 a.C.), tipo } \\
\text { canônico/braços cruzados } \\
\text { (variedade spedos tardio) } \\
\text { - Museu Arqueológico } \\
\text { Nacional de Atenas, Número } \\
\text { de inv. } 3978\end{array}$ & Sapuna-Sakelaraki (19--?, p. 39) \\
\hline 21 & $\begin{array}{l}\text { Mármore } \\
74,3 \mathrm{~cm}\end{array}$ & $?$ & $\begin{array}{l}\text { - Cicládico Antigo II (2.700- } \\
\text { 2.30o a.C.), tipo } \\
\text { canônico/braços cruzados } \\
\text { (variedade spedos tardio) } \\
\text { - Museu de Arte Cicládica, } \\
\text { Número de inv. } 282\end{array}$ & Doumas (1979, p. 104) \\
\hline 22 & Mármore & ? & $\begin{array}{l}\text { - Cicládico Antigo II (2.700- } \\
\text { 2.300 a.C.), tipo }\end{array}$ & Doumas $(1979$, p. 104) \\
\hline
\end{tabular}




\begin{tabular}{|c|c|c|c|c|}
\hline & $70 \mathrm{~cm}$ & & $\begin{array}{l}\text { canônico/braços cruzados } \\
\text { (variedade spedos tardio) } \\
\text { - Museu de Arte Cicládica, } \\
\text { Número de inv. } 257\end{array}$ & \\
\hline 23 & $\begin{array}{l}\text { Mármore } \\
74,5 \mathrm{~cm}\end{array}$ & ? & $\begin{array}{l}\text { - Cicládico Antigo II (2.700- } \\
\text { 2.30o a.C.), tipo } \\
\text { canônico/braços cruzados } \\
\text { (variedade spedos tardio) } \\
\text { - Museu de Arte Cicládica, } \\
\text { Número de inv. } 280\end{array}$ & Doumas (1979, p. 103) \\
\hline 24 & $\begin{array}{l}\text { Mármore } \\
65,5 \mathrm{~cm}\end{array}$ & $?$ & $\begin{array}{l}\text { - Cicládico Antigo II (2.700- } \\
\text { 2.30o a.C.), tipo } \\
\text { canônico/braços cruzados } \\
\text { (variedade spedos tardio) } \\
\text { - Museu de Arte Cicládica, } \\
\text { Número de inv. } 304\end{array}$ & Doumas (1979, p. 106) \\
\hline 25 & $\begin{array}{l}\text { Mármore } \\
26,8 \mathrm{~cm}\end{array}$ & $?$ & $\begin{array}{l}\text { - Cicládico Antigo II (2.700- } \\
\text { 2.30o a.C.), tipo } \\
\text { canônico/braços cruzados } \\
\text { (variedade spedos antigo) } \\
\text { - Museu de Arte Cicládica, } \\
\text { Número de inv. } 283\end{array}$ & Doumas (1979, p. 74) \\
\hline 26 & $\begin{array}{c}\text { Mármore } \\
30 \mathrm{~cm}\end{array}$ & ? & $\begin{array}{l}\text { - Cicládico Antigo II (2.700- } \\
\text { 2.300 a.C.), tipo } \\
\text { canônico/braços cruzados } \\
\text { (variedade spedos tardio, com } \\
\text { características dokathismata) } \\
\text { - Museu J. Paul Getty, Número } \\
\text { de inv. 88.AA.48 }\end{array}$ & $\begin{array}{l}\text { Doumas (2002, p. 84) } \\
\text { The J. Paul Getty Museum. Disponível em: } \\
\text { <http://www.getty.edu/art/gettyguide/art } \\
\text { ObjectDetails?artobj=15045>. Acesso em: } \\
19 \text { jan. 2019. }\end{array}$ \\
\hline 27 & $\begin{array}{l}\text { Mármore } \\
9,5 \mathrm{~cm}\end{array}$ & $?$ & $\begin{array}{l}\text { - Cicládico Antigo II (2.700- } \\
\text { 2.30o a.C.), tipo } \\
\text { canônico/braços cruzados } \\
\text { (variedade spedos tardio, com } \\
\text { características dokathismata) } \\
\text { - Museu de Arte Cicládica, } \\
\text { Número de inv. 350 }\end{array}$ & Doumas (1979, p. 67) \\
\hline 28 & $\begin{array}{l}\text { Mármore } \\
37,5 \mathrm{~cm}\end{array}$ & ? & $\begin{array}{l}\text { - Cicládico Antigo II (2.700- } \\
\text { 2.300 a.C.), tipo } \\
\text { canônico/braços cruzados } \\
\text { (variedade spedos tardio) } \\
\text { - Museu de Artes da Virginia, } \\
\text { Número de inv. } 83.73 \\
\end{array}$ & $\begin{array}{l}\text { Doumas (2002, p. 86) } \\
\text { Virginia Museum of Fine Arts. Disponível } \\
\text { em: } \\
\text { <https://www.vmfa.museum/piction/602 } \\
\text { 7262-62229041/>. Acesso em 19 jan. } 2019 .\end{array}$ \\
\hline 29 & $\begin{array}{c}\text { Pedra verde } \\
30,7 \mathrm{~cm}\end{array}$ & ? & $\begin{array}{l}\text { - Cicládico Antigo II (2.700- } \\
\text { 2.300 a.C.), tipo } \\
\text { canônico/braços cruzados } \\
\text { (variedade dokathismata) } \\
\text { - Museu de Arte Cicládica, } \\
\text { Número de inv. } 310\end{array}$ & Doumas (1979, p. 67) \\
\hline 30 & $\begin{array}{c}\text { Mármore } \\
39,1 \mathrm{~cm}\end{array}$ & ? & $\begin{array}{l}\text { - Cicládico Antigo II (2.700- } \\
2.300 \text { a.C.), tipo } \\
\text { canônico/braços cruzados } \\
\text { (variedade dokathismata) } \\
\text { - Museu de Arte Cicládica, } \\
\text { Número de inv. } 206 \\
\end{array}$ & Doumas (1979, p. 108) \\
\hline 31 & $\begin{array}{c}\text { Mármore } \\
40,6 \mathrm{~cm}\end{array}$ & $?$ & $\begin{array}{l}\text { - Cicládico Antigo II (2.700- } \\
\text { 2.300 a.C.), tipo } \\
\text { canônico/braços cruzados } \\
\text { (variedade dokathismata, } \\
\text { possui características do tipo } \\
\text { chalandriani) } \\
\text { - Museu J. Paul Getty, Número } \\
\text { de inv. 90.AA.114 }\end{array}$ & $\begin{array}{l}\text { Doumas (2002, p. 87) } \\
\text { The J. Paul Getty Museum. Disponível em: } \\
\text { <http://www.getty.edu/art/gettyguide/art } \\
\text { ObjectDetails?artobj=15192>. Acesso em: } \\
19 \text { jan. 2019. }\end{array}$ \\
\hline 32 & $\begin{array}{l}\text { Mármore } \\
12,7 \mathrm{~cm}\end{array}$ & $?$ & $\begin{array}{l}\text { - Cicládico Antigo II (2.700- } \\
\text { 2.300 a.C.), tipo } \\
\text { canônico/braços cruzados } \\
\text { (variedade dokathismata, } \\
\text { possui características do tipo } \\
\text { chalandriani) } \\
\text { - Museu de Arte Cicládica, } \\
\text { Número de inv. } 107\end{array}$ & Doumas (1979, p. 82) \\
\hline 33 & $\begin{array}{l}? \\
\text { ? }\end{array}$ & $?$ & $\begin{array}{l}\text { - Cicládico Antigo II (2.700- } \\
\text { 2.30o a.C.), tipo } \\
\text { canônico/braços cruzados } \\
\text { (variedade spedos antigo) } \\
\end{array}$ & Sapuna-Sakelaraki (19--?, p. 38) \\
\hline
\end{tabular}


Francisco de Assis Sabadini. A Tradição na Produção de Estatuetas Cicládicas

\begin{tabular}{|c|c|c|c|c|}
\hline & & & $\begin{array}{l}\text { - Museu Arqueológico } \\
\text { Nacional de Atenas, Número } \\
\text { de inv. } 6174\end{array}$ & \\
\hline 34 & $\begin{array}{l}\text { Mármore } \\
15,9 \mathrm{~cm}\end{array}$ & ? & $\begin{array}{l}\text { - Cicládico Antigo II (2.700- } \\
\text { 2.300 a.C.), tipo } \\
\text { canônico/braços cruzados } \\
\text { (variedade chalandriani) } \\
\text { - Museu de Arte Cicládica, } \\
\text { Número de inv. } 823\end{array}$ & Doumas (2002, p. 88) \\
\hline 35 & $\begin{array}{l}\text { Mármore } \\
12,7 \mathrm{~cm}\end{array}$ & ? & $\begin{array}{l}\text { - Cicládico Antigo II (2.700- } \\
\text { 2.300 a.C.), tipo pós-canônico } \\
\text { (variedade chalandriani } \\
\text { tardio) } \\
\text { - Museu de Arte Cicládica, } \\
\text { Número de inv. } 105\end{array}$ & $\begin{array}{l}\text { Doumas (1979, p. 82) } \\
\text { Doumas (2002, p. 89) }\end{array}$ \\
\hline 36 & $\begin{array}{l}\text { Mármore } \\
30,5 \mathrm{~cm}\end{array}$ & ? & $\begin{array}{l}\text { - Cicládico Antigo II (2.700- } \\
\text { 2.300 a.C.), tipo pós-canônico } \\
\text { (variedade chalandriani } \\
\text { tardio) } \\
\text { - Museu de Arte Cicládica, } \\
\text { Número de inv. } 102\end{array}$ & Doumas (1979, p. 71) \\
\hline 37 & $\begin{array}{l}\text { Mármore } \\
16,2 \mathrm{~cm}\end{array}$ & ? & $\begin{array}{l}\text { - Cicládico Antigo II (2.700- } \\
\text { 2.300 a.C.), tipo pós-canônico } \\
\text { - Museu de Arte Cicládica, } \\
\text { Número de inv. } 108\end{array}$ & Doumas (1979, p. 83) \\
\hline 38 & $\begin{array}{l}\text { Mármore } \\
14,8 \mathrm{~cm}\end{array}$ & ? & $\begin{array}{l}\text { - Cicládico Antigo II (2.700- } \\
\text { 2.300 a.C.), tipo pós-canônico } \\
\text { - Museu de Arte Cicládica, } \\
\text { Número de inv. } 328\end{array}$ & Doumas (1979, p. 85) \\
\hline 39 & $\begin{array}{l}\text { Mármore } \\
11 \mathrm{~cm}\end{array}$ & ? & $\begin{array}{l}\text { - Cicládico Antigo II (2.700- } \\
2.300 \text { a.C), estatueta de tipo } \\
\text { único no Egeu } \\
\text { - Museu de Arte Cicládica, } \\
\text { Número de inv. } 332\end{array}$ & Doumas (1979, p. 99) \\
\hline
\end{tabular}

